\title{
In Vitro Susceptibilities of Candida albicans Isolates to Antifungal Agents in Tokat, Turkey
}

\author{
Gulgun Yenisehirli ${ }^{1, *}$; Nermin Bulut ${ }^{1}$; Aydan Yenisehirli ${ }^{2}$; Yunus Bulut ${ }^{1}$ \\ ${ }^{1}$ Department of Microbiology and Clinical Microbiology, Faculty of Medicine, Gaziosmanpasa University, Tokat, Turkey \\ ${ }^{2}$ Department of Pharmacology, Faculty of Medicine, Gaziosmanpasa University, Tokat, Turkey \\ *Corresponding author: Gulgun Yenisehirli, Department of Microbiology and Clinical Microbiology, Faculty of Medicine, Gaziosmanpasa University, Tokat, Turkey. Tel: \\ +90-3562129500; +90-3562127209, Fax: +90-3562133176, E-mail: gulgun.yenisehirli@gop.edu.tr
}

Received: February 18, 2015; Revised: June 9, 2015; Accepted: June 16, 2015

\begin{abstract}
Background:Candida albicans is the pathogenic species most commonly isolated from fungal infections. Management of these infections depends on the immune status of the host, severity of disease, and the choice of antifungal drug. In spite of the development of new antifungal drugs, epidemiological studies have shown that resistance to antifungal drugs in C. albicans strains is becoming a serious problem.

Objectives:The aim of this study was to evaluate the in vitro susceptibility of $C$. albicans isolates to ketoconazole, fluconazole, itraconazole, voriconazole, posaconazole, amphotericin B, caspofungin, and anidulafungin.

Materials and Methods: A total of 201 C. albicans isolates were collected from clinical specimens. Antifungal susceptibility tests were performed using the Etest.

Results: All the tested C. albicans isolates were found to be susceptible to amphotericin B and anidulafungin. Although none of the isolates showed resistance to caspofungin, $15 \%$ of the isolates were classified as showing intermediate resistance. The resistance rates of $C$. albicans isolates to ketoconazole, fluconazole, itraconazole, voriconazole and posaconazole were $32 \%, 34 \%, 21 \%, 14 \%$ and $14 \%$, respectively.

Conclusions: Our findings indicate that resistance of C. albicans strains to azoles is more common in Tokat, Turkey. Therefore, a strategy to control the inappropriate and widespread use of antifungal drugs is urgently needed. Fungal culturing and antifungal susceptibility testing will be useful in patient management as well as resistance surveillance.
\end{abstract}

Keywords: Amphotericin B; Azoles; Echinocandins; Antifungal Drug Resistance; Candida albicans

\section{Background}

In the past few decades, the widespread use of broadspectrum antibiotics, corticosteroids, immunosuppressants, and antineoplastic agents has given rise to an increase in fungal infections (1-3). Candida albicans is the pathogenic species most commonly isolated from these fungal infections (4). The management of these infections depends on the immune status of the host, severity of disease, and the choice of antifungal drug (5). Recently, new antifungal drugs have been developed and introduced into clinical use for the treatment of fungal infections. In spite of the development of new antifungal drugs, epidemiological studies have shown that resistance to antifungal drugs in C. albicans strains is becoming a serious problem $(6,7)$.

Triazoles are the most widely used antifungal drugs (3). However, increased use of triazoles in both prophylactic and empiric therapy has resulted in the development of azole resistance in Candida species (6). Many studies have reported increased fluconazole resistance rates in C. albicans isolates $(8,9)$. Voriconazole and posaconazole, which are newer triazoles, have broad-spectrum activity against yeasts and molds, including fluconazole-resistant Candida spp. $(10,11)$. Although voriconazole and posaconazole are active against fluconazole-resistant Candida spp., cross-resistance has been reported $(11,12)$.

The mode of action of echinocandins such as caspofungin and anidulafungin is different from that of azole drugs. Echinocandins act by inhibiting 1,3- $\beta$-glucan synthesis in fungal cells (13). They have fungicidal activity against Candida spp., including those that are resistant to other antifungal agents (14-16). On the other hand, the acquisition of resistance to caspofungin has been observed (17). In vitro antifungal susceptibility testing is an important tool for the selection of a proper antifungal therapy, since increasing antifungal resistance rates in C. albicans strains and treatment failure have been reported frequently $(8,9,17,18)$. Antifungal susceptibility testing also enables a characterization of the changes in antifungal sensitivity patterns of $C$. albicans strains. The agar-based Etest is a useful method for determining in vitro susceptibilities of Candida spp. to the azoles, amphotericin B and caspofungin (19-22).

Copyright (C) 2015, Ahvaz Jundishapur University of Medical Sciences. This is an open-access article distributed under the terms of the Creative Commons Attribution-NonCommercial 4.0 International License (http://creativecommons.org/licenses/by-nc/4.0/) which permits copy and redistribute the material just in noncommercial usages, provided the original work is properly cited. 
Yenisehirli G et al.

\section{Objectives}

The aim of this study was to evaluate the in vitro susceptibility of C. albicans isolates to fluconazole, itraconazole, ketoconazole, voriconazole, posaconazole, amphotericin $\mathrm{B}$, caspofungin, and anidulafungin using the Etest.

\section{Materials and Methods}

A total of 201 C. albicans isolates were collected from clinical specimens submitted to the mycological laboratory of the clinical microbiology department, Gaziosmanpasa university hospital, Tokat, Turkey, between May 2007 and January 2012. Candida albicans isolates were identified by a germ tube test, in which chlamydospore formation on cornmeal agar plus Tween 80 (23) was assayed using an API 20C AUX Commercial System (BioMeriux, Marcy-l' Etoile, France). Isolates were stored in 20\% glycerol at $-80^{\circ} \mathrm{C}$ until use.

Antifungal susceptibility tests were performed using amphotericin B, voriconazole, caspofungin (AB Biodisk, Solna, Sweden), fluconazole, ketoconazole, itraconazole, posaconazole, and anidulafungin (Liofilchem, Teramo, Italy) Etest strips. Etest strips were stored at $-20^{\circ} \mathrm{C}$ until use. The Etest was performed in accordance with the manufacturer's instructions. The agar plates were prepared using RPMI-1640 medium (Sigma, St. Louis, USA) supplemented with $1.5 \%$ agar and $2 \%$ glucose and buffered to a $\mathrm{pH}$ of 7.0 with $0.165 \mathrm{~mol} \mathrm{~L}^{-1}$ MOPS (3-[N-morpholino] propanesulfonic acid) (Sigma, St. Louis, USA). Yeast colonies were suspended in saline and the turbidity of the final inoculum was adjusted to 0.5 McFarland. The agar plates were inoculated by dipping a sterile swab into the suspension and swabbing the agar surface in three different directions. After the plates were allowed to dry in a safety cabinet for $15 \mathrm{~min}$, Etest strips were applied on to the agar surface by using sterile forceps. The plates were incubated in ambi- ent air or at $35^{\circ} \mathrm{C}$ for 24 - 48 hours. The minimum inhibitory concentration (MIC) was determined as $80 \%$ inhibition for the azoles and echinocandins and 100\% inhibition for amphotericin $\mathrm{B}$, and recorded as the drug concentration at the point where the ellipse intersected the MIC scale on the Etest strip. Quality control was performed using Candida albicans ATCC 90028. All tests were performed in duplicate.

Species-specific breakpoints recommended by the Clinical and Laboratory Standards Institute (CLSI) M27-S4 document were used to evaluate the susceptibilities of isolates against voriconazole, fluconazole, itraconazole, caspofungin, and anidulafungin (24). These breakpoints are shown in Table 1. No interpretive criteria for posaconazole, ketoconazole, and amphotericin B are available in the CLSI M27-S4 document. Therefore, for amphotericin $\mathrm{B}$ and ketoconazole, MIC breakpoints recommended by previous researchers were used $(25,26)$, and voriconazole breakpoints were used for posaconazole. Isolates with MICs $<1 \mu \mathrm{g} / \mathrm{mL}$ for amphotericin B, $\leq 0.125 \mu \mathrm{g} / \mathrm{mL}$ for ketoconazole, and $\leq 0.125 \mu \mathrm{g} / \mathrm{mL}$ for posaconazole were considered as susceptible. Isolates with MICs from $0.25 \mu \mathrm{g} /$ $\mathrm{mL}$ to $0.5 \mu \mathrm{g} / \mathrm{mL}$ for ketoconazole was considered as to be dose-dependently susceptible. Isolates with MICs $\leq 0.25$ - $0.5 \mu \mathrm{g} / \mathrm{mL}$ for posaconazole were considered to show intermediate resistance. Isolates with MICs $\geq 2 \mu \mathrm{g} / \mathrm{mL}$ for amphotericin $\mathrm{B}, \quad \geq 1 \mu \mathrm{g} / \mathrm{mL}$ for ketoconazole, or $\geq 1 \mu \mathrm{g} / \mathrm{mL}$ for posaconazole were considered as resistant.

\section{Results}

The resistance rates, MIC ranges, MIC50 values, and MIC90 values of fluconazole, itraconazole, ketoconazole, voriconazole, posaconazole, amphotericin B, caspofungin, and anidulafungin for all the C. albicans isolates are summarized in Table 2 .

\begin{tabular}{|c|c|c|c|c|}
\hline C. albicans & Susceptible & Susceptible Dose-Dependent & Intermediate & Resistant \\
\hline \multicolumn{5}{|l|}{ Fluconazole } \\
\hline M27-A3 BP & $\leq 8$ & $16-32$ & - & $\geq 64$ \\
\hline M27-S4 BP & $\leq 2$ & 4 & - & $\geq 8$ \\
\hline Itraconazole & $\leq 0.12$ & $0.25-0.5$ & - & $\geq 1$ \\
\hline \multicolumn{5}{|l|}{ Voriconazole } \\
\hline M27-A3 BP & $\leq 1$ & - & 2 & $\geq 4$ \\
\hline M27-S4 BP & $\leq 0.12$ & - & $0.25-0.5$ & $\geq 1$ \\
\hline \multicolumn{5}{|l|}{ Caspofungin } \\
\hline M27-А3 BР & $\leq 2$ & - & - & - \\
\hline M27-S4 BP & $\leq 0.25$ & - & 0.5 & $\geq 1$ \\
\hline \multicolumn{5}{|c|}{ Anidulafungin } \\
\hline M27-A3 BP & $\leq 2$ & - & - & - \\
\hline M27-S4 BP & $\leq 0.25$ & - & 0.5 & $\geq 1$ \\
\hline
\end{tabular}


Yenisehirli G et al.

Table 2. In Vitro Activities of Fluconazole, Itraconazole, Ketoconazole, Voriconazole, Posaconazole, Amphotericin B, Caspofungin and Anidulafungin Against 201 Candida albicans Isolates

\begin{tabular}{|c|c|c|c|c|}
\hline \multirow[t]{2}{*}{ Antifungal Agents } & \multicolumn{3}{|c|}{ MIC, $\mu \mathrm{g} / \mathrm{mL}$} & \multirow[t]{2}{*}{ Resistant $^{\mathrm{a}}$} \\
\hline & Range & $\mathbf{5 0} \%$ & 90\% & \\
\hline Fluconazole & $0.064-256$ & 1 & $>256$ & $69(34)$ \\
\hline Itraconazole & $0.004-32$ & 0.016 & $>32$ & $42(21)$ \\
\hline Ketoconazole & $0.002-32$ & 0.016 & $>32$ & $64(32)$ \\
\hline Voriconazole & $0.002-32$ & 0.012 & $>32$ & $29(14)$ \\
\hline Posaconazole & $0.004-32$ & 0.047 & $>32$ & $29(14)$ \\
\hline Amphotericin B & $0.003-0.25$ & 0.016 & 0.064 & $0(0)$ \\
\hline Anidulafungin & $<0.002-0.006$ & $<0.002$ & 0.002 & $0(0)$ \\
\hline Caspofungin & $0.012-0.5$ & 0.19 & 0.38 & $0(0)$ \\
\hline
\end{tabular}

a Data are presented as No.(\%).

MIC values of 201 C. albicans strains were in the range of $0.003-0.25 \mu \mathrm{g} / \mathrm{mL}$ for amphotericin B. All tested C. albicans isolates were found to be susceptible to amphotericin B and anidulafungin. For anidulafungin, the MIC values ranged between $<0.002 \mu \mathrm{g} / \mathrm{mL}$ and $0.006 \mu \mathrm{g} / \mathrm{mL}$ and the majority of isolates (96\%) had MIC values $<0.002 \mu \mathrm{g} / \mathrm{mL}$. On the other hand, for caspofungin, $15 \%$ of the isolates were determined to show intermediate resistance. The resistance rates of C. albicans isolates to ketoconazole, fluconazole, itraconazole, voriconazole and posaconazole were $32 \%, 34 \%, 21 \%, 14 \%$, and $14 \%$, respectively. All fluconazole resistant isolates had MIC values $>256 \mu \mathrm{g} / \mathrm{mL}$. A total of $29(14 \%)$ isolates were determined to be resistant to all tested azoles. Only three $(1.5 \%)$ C. albicans isolates were classified as dose-dependently susceptible to fluconazole according to revised CLSI breakpoints. Four isolates (2\%) were found to be dose-dependently susceptible to itraconazole, whereas 2 isolates $(1 \%)$ were dose-dependently susceptible to ketoconazole. None of the tested isolates was categorized to show intermediate resistance to voriconazole, although ten isolates (5\%) were determined to show intermediate resistance to posaconazole. All the isolates that showed intermediate resistance to posaconazole were found to be susceptible to voriconazole.

\section{Discussion}

In this study, we found that all isolates were susceptible to amphotericin B. Similar results have been observed in previous studies in our country and the other European countries (27-30). Messer et al. have measured the MIC range for amphotericin $\mathrm{B}$ as $0.12-2 \mathrm{mg} / \mathrm{L}$ in an international surveillance study (31). On the other hand, Santhanam et al. (32) have documented amphotericin B MICs ranging from 0.25 to $16 \mathrm{mg} / \mathrm{L}$ in Malaysia. Recently, Badiee and Alborzi (12) have reported the resistance rate of C. albicans isolates to amphotericin B was 7\% in Southern Iran. In our study, 34\% of the C. albicans isolates with MIC90 $>256 \mathrm{mg} / \mathrm{L}$ were found to be resistant to fluconazole.
Similarly, Zarei Mahmoudabadi et al. (33) showed that $55.2 \%$ of the C. albicans strains isolated from candiduria were resistant to fluconazole. In another study reported by the same authors, the resistance rate of C. albicans to fluconazole was $59.2 \%$ (34). In contrast to our findings, previous studies have reported low resistance rates for fluconazole $(28,30,32,35-38)$. The resistance rates to fluconazole, itraconazole, and voriconazole in our study were also higher than those reported in a previous study conducted in a region west of Turkey between 2008 and 2009 (27). Variation of these resistance rates may result from differences in the patient population, prior exposure to azoles, and different breakpoint values. It is important to emphasize that CLSI has recently established new species-specific MIC breakpoints to evaluate susceptibility to fluconazole, itraconazole, and voriconazole in C. albicans strains. Therefore, C. albicans isolates for which the fluconazole MIC was $\geq 8 \mathrm{mg} / \mathrm{L}$ were considered nonsusceptible in this study; the MIC limit previously was $\geq$ $64 \mathrm{mg} / \mathrm{L}$. Fothergill et al. (39) have evaluated the effect of new MIC breakpoints on azole and echinocandin resistance patterns in Candida species; the resistance rates in C. albicans isolates according to the new CLSI criteria were found to be higher than those determined previously.

Among the 69 fluconazole-resistant isolates, 38 (55\%) were also resistant to both ketoconazole and itraconazole, 29 (42\%) were resistant to ketoconazole, itraconazole, voriconazole, and posaconazole. Previous studies have documented that decreased susceptibility to fluconazole is associated with decreased susceptibility to other azoles (10, 35, 40, 41). Barchiesi et al. (42) have detected that the MICs of itraconazole for fluconazole-resistant $C$. albicans isolates were significantly higher than those for fluconazole-susceptible isolates, indicating cross-resistance between azoles. Numerous azole resistance mechanisms have been described, such as the induction of $C D R$ and MDR genes-encoded efflux pumps, overexpression of 14- $\alpha$ demethylase, modification of the target enzyme structure, alteration of the ergosterol synthesis pathway, 
reduction of fungal membrane permeability, etc. Induction of the CDR gene-encoded efflux pump and modification of target enzyme structure can result in triazole resistance in C. albicans strains, whereas induction of the $M D R$ gene-encoded efflux pump is only responsible for fluconazole resistance (6). In our study, resistance rates to itraconazole among C. albicans strains were lower than those for ketoconazole and fluconazole. Cartledge et al. (40) have suggested that resistance associated with a reduction in fungal membrane permeability might result in resistance to ketoconazole and fluconazole rather than to itraconazole, because itraconazole is more lipid soluble than ketoconazole and fluconazole.

Many authors have documented that azole resistance in Candida strains has been associated with previous exposure to fluconazole $(3,5,6,38,40)$. The widespread use of fluconazole, due to its relative safety and high oral bioavailability, for treatment and prophylaxis in our region may be the cause of the high azole resistance rates observed in our study. In addition, the availability of azole drugs without a prescription in our country may contribute to the development of azole resistance. All C. albicans isolates were susceptible to anidulafungin. Similar results have been reported by Fothergill et al. and Arendrup et al. $(39,43)$. In contrast to our findings, Faria-Ramos et al. (29) have documented the rate of anidulafungin resistance as $4 \%$ in C. albicans isolates. Resistance to caspofungin among C. albicans isolates has been reported by previous researchers $(29,43)$. Ghahri et al. (44) have observed that the MIC range for caspofungin as 0.125 - 4 $\mathrm{mg} / \mathrm{L}$ in Candida species isolated from blood specimens. Although none of the isolates was found to be resistant to caspofungin, based on the new CLSI criteria, $15 \%$ of isolates were classified as showing intermediate resistance.

Our findings indicate that azole resistance in C. albicans strains is more common in our region. High azole resistance rates must be considered when selecting antifungal drugs for treatment or prophylaxis. Fungal culturing and antifungal susceptibility testing will be useful in patient management as well as resistance surveillance. We urgently need a strategy to control the inappropriate and widespread use of antifungal drugs. Application of antifungal control programs may contribute to prevent the increase of antifungal resistance.

\section{Authors' Contributions}

Study concept and design: Gulgun Yenişehirli, Yunus Bulut. Acquisition of data: Nermin Bulut. Analysis and interpretation of data: Aydan Yenisehirli. Drafting of the manuscript: Gulgun Yenisehirli. Critical revision of the manuscript for important intellectual content: Aydan Yenisehirli.

\section{Funding/Support}

This study was supported by the Gaziosmanpasa university research fund, project no:2011/07.

\section{References}

1. Ortega M, Marco F, Soriano A, Almela M, Martinez JA, Lopez J, et al. Candida species bloodstream infection: epidemiology and outcome in a single institution from 1991 to 2008. J Hosp Infect. 2011;77(2):157-61.

2. Holzheimer RG, Dralle H. Management of mycoses in surgical patients - review of the literature. Eur J Med Res. 2002;7(5):200-26.

3. Lass-Florl C. The changing face of epidemiology of invasive fungal disease in Europe. Mycoses. 2009;52(3):197-205.

4. Pfaller MA, Diekema DJ. Epidemiology of invasive candidiasis: a persistent public health problem. Clin Microbiol Rev. 2007;20(1):133-63.

5. White TC, Marr KA, Bowden RA. Clinical, cellular, and molecular factors that contribute to antifungal drug resistance. Clin Microbiol Rev.1998;11(2):382-402.

6. Masia Canuto M, Gutierrez Rodero F. Antifungal drug resistance to azoles and polyenes. Lancet Infect Dis. 2002;2(9):550-63.

7. Mukherjee PK, Sheehan D, Puzniak L, Schlamm H, Ghannoum MA. Echinocandins: are they all the same? J Chemother. 2011;23(6):319-25.

8. Grant SM, Clissold SP. Fluconazole. A review of its pharmacodynamic and pharmacokinetic properties, and therapeutic potential in superficial and systemic mycoses. Drugs.1990;39(6):877-916.

9. Antoniadou A, Torres HA, Lewis RE, Thornby J, Bodey GP, Tarrand JP, et al. Candidemia in a tertiary care cancer center: in vitro susceptibility and its association with outcome of initial antifungal therapy. Medicine (Baltimore). 2003;82(5):309-21.

10. Nguyen $\mathrm{MH}$, Yu CY. Voriconazole against fluconazole-susceptible and resistant candida isolates: in-vitro efficacy compared with that of itraconazole and ketoconazole. J Antimicrob Chemother. 1998;42(2):253-6

11. Sabatelli F, Patel R, Mann PA, Mendrick CA, Norris CC, Hare R, et al. In vitro activities of posaconazole, fluconazole, itraconazole, voriconazole, and amphotericin B against a large collection of clinically important molds and yeasts. Antimicrob Agents Chemother. 2006;50(6):2009-15.

12. Badiee P, Alborzi A. Susceptibility of clinical Candida species isolates to antifungal agents by E-test, Southern Iran: A five year study. Iran J Microbiol. 2011;3(4):183-8.

13. Rogers TR, Johnson EM, Munro C. Echinocandin antifungal drug resistance. J Invasive Fungal Infect. 2007:199-205.

14. Nelson PW, Lozano-Chiu M, Rex JH. In vitro growth-inhibitory activity of pneumocandins L-733,560 and L-743,872 against putatively amphotericin B- and fluconazole-resistant Candida isolates: influence of assay conditions. J Med Vet Mycol. 1997;35(4):285-7.

15. Pfaller MA, Boyken L, Hollis RJ, Messer SA, Tendolkar S, Diekema DJ. In vitro susceptibilities of Candida spp. to caspofungin: four years of global surveillance. J Clin Microbiol. 2006;44(3):760-3.

16. Messer SA, Diekema DJ, Boyken L, Tendolkar S, Hollis RJ, Pfaller MA. Activities of micafungin against 315 invasive clinical isolates of fluconazole-resistant Candida spp. J Clin Microbiol. 2006;44(2):324-6.

17. Baixench MT, Aoun N, Desnos-Ollivier M, Garcia-Hermoso D Bretagne S, Ramires S, et al. Acquired resistance to echinocandins in Candida albicans: case report and review. J Antimicrob Chemother. 2007;59(6):1076-83.

18. Kontoyiannis DP, Lewis RE. Antifungal drug resistance of pathogenic fungi. Lancet. 2002;359(9312):1135-44.

19. Chryssanthou E, Cuenca-Estrella M. Comparison of the Antifungal Susceptibility Testing Subcommittee of the European Committee on Antibiotic Susceptibility Testing proposed standard and the E-test with the NCCLS broth microdilution method for voriconazole and caspofungin susceptibility testing of yeast species. J Clin Microbiol. 2002;40(10):3841-4.

20. Pfaller MA, Messer SA, Mills K, Bolmstrom A, Jones RN. Evaluation of Etest method for determining posaconazole MICs for 314 clinical isolates of Candida species. JClin Microbiol. 2001;39(11):3952-4.

21. Pfaller MA, Messer SA, Bolmstrom A. Evaluation of Etest for determining in vitro susceptibility of yeast isolates to amphotericin B. Diagn Microbiol Infect Dis. 1998;32(3):223-7.

22. Pfaller MA, Messer SA, Mills K, Bolmstrom A, Jones RN. Evaluation 
of Etest method for determining caspofungin (MK-0991) susceptibilities of 726 clinical isolates of Candida species. J Clin Microbiol. 2001;39(12):4387-9.

23. Larone D. Medically important fungi: a guide to identification. 4 ed. Washington, DC:ASM Press; 2002.

24. Clinical and Laboratory Standards Institute . Reference method for broth dilution antifungal susceptibility testing of yeasts; Fourth informational supplement. .Wayne: CLSI document M27-S4; 2012.

25. Pfaller MA, Espinel-Ingroff A, Canton E, Castanheira M, CuencaEstrella M, Diekema DJ, et al. Wild-type MIC distributions and epidemiological cutoff values for amphotericin B, flucytosine, and itraconazole and Candida spp. as determined by CLSI broth microdilution. JClin Microbiol. 2012;50(6):2040-6.

26. Candido RC, Toloi MR, Franceschini SA, Garcia FR, Minto EC. In vitro activity of antimycotic agents determined by E-test method against vaginal Candida species. Mycopathologia. 1998;144(1):15-20.

27. Bicmen C, Doluca M, Gulat S, Gunduz AT, Tuksavul F. Species level identification and antifungal susceptibility of yeasts isolated from various clinical specimens and evaluation of Integral System Yeasts Plus. New Microbiol. 2012;35(3):327-34.

28. Fleck R, Dietz A, Hof H. In vitro susceptibility of Candida species to five antifungal agents in a German university hospital assessed by the reference broth microdilution method and Etest. J Antimicrob Chemother. 2007;59(4):767-71.

29. Faria-Ramos I, Neves-Maia J, Ricardo E, Santos-Antunes J, Silva AT, Costa-de-Oliveira S, et al. Species distribution and in vitro antifungal susceptibility profiles of yeast isolates from invasive infections during a Portuguese multicenter survey. Eur J Clin Microbiol Infect Dis. 2014;33(12):2241-7.

30. Bourgeois N, Dehandschoewercker L, Bertout S, Bousquet PJ, Rispail P, Lachaud L. Antifungal susceptibility of 205 Candida spp. isolated primarily during invasive Candidiasis and comparison of the Vitek 2 system with the CLSI broth microdilution and Etest methods. J Clin Microbiol. 2010;48(1):154-61.

31. Messer SA, Moet GJ, Kirby JT, Jones RN. Activity of contemporary antifungal agents, including the novel echinocandin anidulafungin, tested against Candida spp., Cryptococcus spp., and Aspergillus spp.: report from the SENTRY Antimicrobial Surveillance Program (2006 to 2007). J Clin Microbiol. 2009;47(6):1942-6.

32. Santhanam J, Nazmiah N, Aziz MN. Species distribution and antifungal susceptibility patterns of Candida species: Is low susceptibility to itraconazole a trend in Malaysia? Med J Malaysia. 2013;68(4):343-7.

33. Zarei Mahmoudabadi A, Zarrin M, Beheshti Fard M. Antifungal susceptibility of Candida species isolated from candidura. Jundishapur J Microbiol. 2012;6(1):24-8.
34. Zarei Mahmoudabadi A, Zarrin M, Kiasat N. Biofilm Formation and Susceptibility to Amphotericin B and Fluconazole in Candida albicans. Jundishapur J Microbiol. 2014;7(7):e17105.

35. Pfaller MA, Messer SA, Boyken L, Rice C, Tendolkar S, Hollis RJ, et al. Use of fluconazole as a surrogate marker to predict susceptibility and resistance to voriconazole among 13,338 clinical isolates of Candida spp. Tested by clinical and laboratory standards institute-recommended broth microdilution methods. J Clin $\mathrm{Mi}$ crobiol. 2007;45(1):70-5.

36. Santos ER, Dal Forno CF, Hernandez MG, Kubica TF, Venturini TP, Chassot F, et al. Susceptibility of Candida spp. isolated from blood cultures as evaluated using the M27-A3 and new M27-S4 approved breakpoints. Rev Inst Med Trop Sao Paulo. 2014;56(6):477-82.

37. Pfaller MA, Messer SA, Boyken L, Tendolkar S, Hollis RJ, Diekema DJ. Selection of a surrogate agent (fluconazole or voriconazole) for initial susceptibility testing of posaconazole against Candida spp.: results from a global antifungal surveillance program.J Clin Microbiol. 2008;46(2):551-9.

38. Shokohi T, Bandalizadeh Z, Hedayati MT, Mayahi S. In vitro antifungal susceptibility of Candida species isolated from orofaringeal lesions of patients with cancer to some antifungal agents. JundishapurJ Microbiol. 2011;4:19-26.

39. Fothergill AW, Sutton DA, McCarthy DI, Wiederhold NP. Impact of new antifungal breakpoints on antifungal resistance in Candida species. J Clin Microbiol. 2014;52(3):994-7.

40. Cartledge JD, Midgley J, Gazzard BG. Clinically significant azole cross-resistance in Candida isolates from HIV-positive patients with oral candidosis. AIDS. 1997;11(15):1839-44.

41. Haddadi P, Zareifar S, Badiee P, Alborzi A, Mokhtari M, Zomorodian $\mathrm{K}$, et al. Yeast colonization and drug susceptibility pattern in the pediatric patients with neutropenia. Jundishapur J Microbiol. 2014;7(9):e11858.

42. Barchiesi F, Colombo AL, McGough DA, Fothergill AW, Rinaldi MG. In vitro activity of itraconazole against fluconazole-susceptible and -resistant Candida albicans isolates from oral cavities of patients infected with human immunodeficiency virus. Antimicrob Agents Chemother.1994;38(7):1530-3.

43. Arendrup MC, Pfaller MA, Danish Fungaemia Study G. Caspofungin Etest susceptibility testing of Candida species: risk of misclassification of susceptible isolates of C. glabrata and C. krusei when adopting the revised CLSI caspofungin breakpoints. Antimicrob Agents Chemother. 2012;56(7):3965-8.

44. Ghahri M, Mirhendi H, Zomorodian K, Kondori N. Identification and antifungal susceptibility patterns of Candida strains isolated from blood specimens in Iran. Arch Clin Infect Dis. 2013;8(3):14529. 